\title{
Acute Toxicity Test with Daphnia magna: An Alternative to Mammals in the Prescreening of Chemical Toxicity?
}

\author{
Lúcia Guilhermino, ${ }^{* 1}$ Teresa Diamantino, $\dagger$ M. Carolina Silva,* and A. M. V. M. Soares $\dagger$ \\ *Instituto de Ciências Biomédicas de Abel Salazar, Departamento de Estudos de Populações, Laboratório de Ecotoxicologia/Centro de Investigação Marinha \\ e Ambiental, Universidade do Porto, Largo Prof. Abel Salazar, 2, 4050 Porto, Portugal; and $\dagger$ Instituto do Ambiente e Vida/Departamento de Zoologia, \\ Universidade de Coimbra, Lg. Marquês de Pombal, 3000 Coimbra Codex, Portugal
}

In this study, the association between the acute toxicity of 15 compounds to Daphnia magna, expressed as 24- and 48-h $\mathrm{LC}_{50}$ values, and the corresponding oral $\mathrm{LD}_{50}$ values for the rat was tested. Since there was evidence of a strong relationship between the two species, the sample was extended to 54 cases by including the values for acute toxicity to $D$. magna and rat of more chemicals published by other authors. Thus, a total of 54 data points were further used to ascertain the relationship between the acute toxicity of chemical compounds to $D$. magna and that to the rat. To summarize its validity, the $D$. magna test is more specific than sensitive as an indicator of toxicity to the rat. When it is used with a chemical that has a high probability of being very toxic to $D$. magna $\left(\mathrm{LC}_{50}<0.22 \mathrm{mg} / \mathrm{L}\right)$, the test provides considerable information if it is positive, virtually giving evidence of toxicity to the rat (with a probability of 0.83 ). On the other hand, a negative test (D. magna $\left.\mathrm{LC}_{50}>0.22 \mathrm{mg} / \mathrm{L}\right)$ has a probability of correctly assigning nontoxicity to the rat equal to 0.74 . This study and results published by other authors provide good evidence of the applicability of using invertebrate tests as prescreening methods, thus considerably reducing the number of mammals required in toxicity testing. (c) 2000 Academic Press

Key Words: Daphnia magna; mammals; rat; acute toxicity; prescreening method.

\section{INTRODUCTION}

In 1959, Russell and Burch in their book, The Principles of Humane Experimental Technique, formally proposed the "3 R's" concept: reduction, refinement, and replacement. Since then, alternative methods to experimentation with highly sensitive animals, particularly mammals, have been developed and some have been introduced in toxicology. The recognition that a precise $\mathrm{LD}_{50}$ value for mammals is not required for notification of new chemicals leads to the

\footnotetext{
${ }^{1}$ To whom correspondence should be addressed. Fax: +351-2-2062232. E-mail: lguilher@ICBAS.up.pt.
}

development of alternative methods to the traditional $\mathrm{LD}_{50}$ test for acute oral toxicity determination. Some of these methods (fixed dose procedure, acute toxic class method, and up-and-down procedure) have now been accepted for regulatory purposes and must be used preferentially to the $\mathrm{LD}_{50}$ test (Tichias et al., 1998).

Studies published in the last decades suggest that acute tests with invertebrates may be used as first screening methods for the assessment of the lethal toxicity of new chemicals to mammals and humans. For example, Neuhauser and collaborators $(1985 \mathrm{a}, \mathrm{b})$ proposed a rank classification of substances based on acute toxicity $\left(\mathrm{LC}_{50}\right.$ values) to the earthworm Eisenia foetida which corresponds to the actual classification based on rat $\mathrm{LD}_{50}$ values, while Khangarot and co-workers (Khangarot and Ray, 1988; Khangarot et al., 1987) found a high correlation between the acute toxicity of some metals to the crustacean cladoceran Daphnia magna and the corresponding $\mathrm{LD}_{50}$ values for the mouse and rat. Furthermore, a study published some years ago by Calleja and Persoone (1992) reports the predictive screening potential of some aquatic invertebrate tests for acute oral toxicity in humans better than the rat $\mathrm{LD}_{50}$ test for some chemicals. The major advantage of using invertebrate bioassays as prescreening methods is reduction of the number of mammals required for toxicity testing. Since these methods are in vivo tests, the biotransformation of chemicals is taken into account and, from this point of view, they seem to be preferable to in vitro methods that have been considered to evaluate human acute toxicity (Ekwall et al., 1989, 1998) for some purposes. In addition, they are less expensive than bioassays with mammals and require less space. The main difficulty in the use of invertebrate tests as prescreening tests is the difference of biological organization level relative to mammals. Although this difference should be considered, it should be remembered that the objective is using them as prescreening methods. Therefore, a final bioassay with a small number of mammals should be carried out. Despite this requirement, the routine use of 
invertebrate tests will represent a significant reduction in the number of mammals used for regulatory purposes.

In this study, the association between the acute toxicity of 15 compounds to Daphnia magna, expressed as 24- and 48-h $\mathrm{LC}_{50}$ values, and the corresponding oral $\mathrm{LD}_{50}$ values to the rat was investigated. Since there was evidence of a strong relationship between the two species, the sample was expanded to 54 cases by including values for acute toxicity to D. magna and rat of more chemicals published by other authors. Thus, a total of 54 data points were further used to ascertain the relationship between acute toxicity of chemical compounds to D. magna and the rat.

\section{MATERIAL AND METHODS}

Parent animals. Parent animals were individually cultured in $100 \mathrm{~mL}$ of ASTM hard water (ASTM, 1980) with an organic additive (Baird et al., 1989b) and fed Chlorella vulgaris $(0.322 \mathrm{mg}$ carbon/day). The photoperiod was $16 \mathrm{~h}$ $\mathrm{L}: 8 \mathrm{~h} \mathrm{D}$ and the temperature was $20 \pm 1^{\circ} \mathrm{C}$.

Acute Daphnia toxicity tests. All experiments were carried out with animals from clone A (Baird et al., 1989a) and initiated with third to fifth brood neonates $(<24 \mathrm{~h}$ old $)$. Test medium was ASTM hard water (ASTM, 1980) and the animals were not fed during the tests. Twenty animals per treatment in groups of five per $100 \mathrm{~mL}$ of test solution were used. Temperature and photoperiod were as described above. Oxygen concentrations and $\mathrm{pH}$ levels were determined 0,24 , and $48 \mathrm{~h}$ after the start of the test. The measured effect was death recognized as immobilization for $15 \mathrm{~s}$ after stimulation by a bright light.

Test solutions. Tested substances were paraoxon, parathion, chlorpyrifos, 3, 4-dichloroaniline (DCA), cadmium choride, mercurous chloride, copper sulfate, zinc sulfate, chromous chloride, sodium dichromate, potassium dichromate, sodium bromide, sodium dodecyl sulfate (SDS), dodecyl benzyl sulfonate (DBS), ethanol, and methanol. For each chemical, test concentrations were prepared by dilution with ASTM hard water of a stock solution in nanopure water (conductivity $5 \mu \mathrm{S} / \mathrm{cm}$ ), except for parathion for which the stock solution was prepared in ethanol. Actual concentrations of DCA, parathion, and chlorpyrifos, considered difficult substances, were measured by HPLC (Carvalho et al., 1985; Guilhermino et al., 1996). For all the other chemicals, nominal concentrations were used.

Chemicals. Metallic compounds, SDS, methanol, and ethanol were purchased from Merck (Germany), DBS was a gift of Unilever UK Central Resources Ltd., parathion was from BDH (England), paraoxon was from Sigma (St. Louis, MO), chlorpyrifos was from Riedel-de Haën (Germany), and DCA from Aldrich (England). All chemicals were at least $95 \%$ pure.
Data analysis. $\mathrm{LC}_{50}$ values to $D$. magna and respective $95 \%$ confidence limits were determined by probit analysis (Finney, 1971). The Pearson product-moment correlation coefficient was used to test the association between the oral $\mathrm{LD}_{50}$ to the rat and both 24-h $\mathrm{LC}_{50}$ and $48-\mathrm{h} \mathrm{CC}_{50}$ to $D$. magna using 15 compounds as test substances. Since there was evidence of a strong relationship, a revision of the literature values for rat oral $\mathrm{LD}_{50}$ values and D. magna $24-\mathrm{h}$ $\mathrm{LC}_{50}$ values was performed, and 54 data points were further used to ascertain the relationship between D. magna $\mathrm{LC}_{50}$ values and the acute toxicity to the rat based on the EU classification of chemicals. Two groups were formed: a group of both very toxic and toxic chemicals (oral $\mathrm{LD}_{50}$ $<200 \mathrm{mg} / \mathrm{kg}$ ) and a group of chemicals considered harmful or unclassified (oral $\mathrm{LD}_{50} \geq 200 \mathrm{mg} / \mathrm{kg}$ ). A logistic regression model was then used to determine the "best" cutpoint in the 24-h $\mathrm{LC}_{50}$ values that could predict the toxicity to the rat (Hosmer and Lemeshow, 1989). This cutpoint can then be considered as a confirmation test for rat toxicity, and its criterion validity (Abramson, 1984) is also discussed, using as criteria the sensitivity, specificity, and relative risk.

\section{RESULTS}

$\mathrm{LC}_{50}$ values of 15 compounds for D. magna determined in this study and the corresponding oral $\mathrm{LD}_{50}$ values for the rat found in the literature are listed in Table 1. For these chemicals, the correlation coefficients between $\mathrm{LD}_{50}$ values for the rat and both 24- and 48-h $\mathrm{LC}_{50}$ values for D. magna (in logarithm scale to improve the assumption of normality) were highly significant. The value of $r$ was 0.93 using D. magna 24-h $\mathrm{LC}_{50}$ values and 0.91 using D. magna $48-\mathrm{h}$ $\mathrm{LC}_{50}$ values. With the data in Table 2, a linear regression was used to model the probability of toxicity to the rat using as predictor the 24-h $\mathrm{LC}_{50}$ values for D. magna for the 54 chemicals in Table 2. The value of $r$ was low (0.478), and for this reason, a logistic regression model was then used. As judged by the goodness-of-fit $\chi^{2} P$ value (0.19), the model fit the data. Figure 1 is the logistic curve, the value of $\ln \left(L_{50}\right)$ that serves as a "test" to predict the probability of toxicity to the rat $(-1.50)$ and the chemicals the toxicity of which is wrongly predicted by the model. Two of them are false positives (predicted as toxic and actually classified as harmful) and 11 are false negatives (predicted as not toxic and actually classified as toxic).

Using $0.22 \mathrm{mg} / \mathrm{L}$ as text value, the criterion validity of D. magna $24-\mathrm{hCC}_{50}$ to predict toxicity to the rat is presented in Table 3. The D. magna test has a high specificity, correctly identifying $93.9 \%$ of the chemicals that are nontoxic to the rat, and consequently a low false-positive rate (2/12). Nevertheless, its sensitivity is rather low, indicating toxicity in only $47.6 \%$ of the chemicals that are in fact toxic to the rat. An overall measure of validity, which takes account of both toxic and nontoxic substances to the rat, is 
TABLE 1

$\mathrm{LC}_{50}$ Values at 24 and $48 \mathrm{~h}(\mathrm{mg} / \mathrm{L})$ and Respective $95 \%$ Confidence Limits of 15 Chemical Compounds Determined in This Study for $D$. magna and the Corresponding Oral $\mathbf{L D}_{50}$ $(\mathrm{mg} / \mathrm{kg})$ Values for the Rat

\begin{tabular}{|c|c|c|c|}
\hline \multirow[b]{2}{*}{ Chemical } & \multicolumn{2}{|c|}{ D. magna $\mathrm{LC}_{50}(\mathrm{mg} / \mathrm{L})$} & \multirow{2}{*}{$\begin{array}{l}\text { Rat oral } \mathrm{LD}_{5 \mathrm{c}} \\
(\mathrm{mg} / \mathrm{kg})\end{array}$} \\
\hline & $24 \mathrm{~h}$ & $48 \mathrm{~h}$ & \\
\hline Paraoxon & $\begin{array}{c}0.00055 \\
(0.00052-0.00057)\end{array}$ & $\begin{array}{c}0.00019 \\
(0.00018-0.00020)\end{array}$ & $1.8^{a}$ \\
\hline Parathion & $\begin{array}{c}0.00219 \\
(0.00217-0.00221)\end{array}$ & $\begin{array}{c}0.00216 \\
(0.00215-0.00217)\end{array}$ & $13^{b}$ \\
\hline DCA & $\begin{array}{c}0.271 \\
(0.269-0.274)\end{array}$ & $\begin{array}{c}0.100 \\
(0.099-0.101)\end{array}$ & $648^{c}$ \\
\hline Chlorpyrifos & $*$ & $\begin{array}{c}0.344 \\
(0.343-0.345)\end{array}$ & $145^{c}$ \\
\hline Mercurous chloride & $\begin{array}{c}0.0027 \\
(0.0026-0.0028)\end{array}$ & $\begin{array}{c}0.002 \\
(0.0019-0.0021)\end{array}$ & $37^{a}$ \\
\hline Cadmium chloride & $\begin{array}{c}0.071 \\
(0.032-0.159)\end{array}$ & $\begin{array}{c}0.017 \\
(0.0166-0.0174)\end{array}$ & $88^{a}$ \\
\hline Copper sulfate & $\begin{array}{c}0.399 \\
(0.391-0.406)\end{array}$ & $\begin{array}{c}0.0826 \\
(0.0823-0.0829)\end{array}$ & $960^{a}$ \\
\hline Zinc sulfate & $\begin{array}{c}35.403 \\
(28.360-44.192)\end{array}$ & $\begin{array}{c}4.029 \\
(3.999-4.056)\end{array}$ & $2,150^{a}$ \\
\hline Sodium dichromate & $\begin{array}{c}1.854 \\
(1.813-1.895)\end{array}$ & $\begin{array}{c}0.778 \\
(0.777-0.779)\end{array}$ & $160^{d}$ \\
\hline Chromous chloride & $\begin{array}{c}40.507 \\
(33.980-48.287)\end{array}$ & $\begin{array}{c}21.531 \\
(18.957-24.456)\end{array}$ & $1,870^{a}$ \\
\hline Sodium bromide & $\begin{array}{c}15,322 \\
(14,613-16,065)\end{array}$ & $\begin{array}{c}7451 \\
(7394-7508)\end{array}$ & $3,500^{a}$ \\
\hline Ethanol & $\begin{array}{c}9,788 \\
(7,387-12,970)\end{array}$ & $\begin{array}{c}5,680 \\
(4364-7392)\end{array}$ & $13,700^{e}$ \\
\hline Methanol & $\begin{array}{c}4,816 \\
(3,616-6,414)\end{array}$ & $\begin{array}{c}3,289 \\
(2461-4395)\end{array}$ & $13,000^{e}$ \\
\hline SDS & $\begin{array}{c}45.898 \\
(45.697-46.101)\end{array}$ & $\begin{array}{c}19.129 \\
(19.023-19.235)\end{array}$ & $1,288^{a}$ \\
\hline DBS & $\begin{array}{c}38.514 \\
(37.452-39.605)\end{array}$ & $\begin{array}{c}9.546 \\
(9.491-9.600)\end{array}$ & $2,000^{a}$ \\
\hline
\end{tabular}

${ }^{a}$ Merck (1989).

${ }^{b}$ Gaines (1969).

${ }^{c}$ Merck, personal communication.

${ }^{d}$ Anger et al. (1986).

${ }^{e}$ NIOSH (1977).

*It was not possible to calculate the $\mathrm{LC}_{50}$ at $24 \mathrm{~h}$.

the relative risk of toxicity to the rat, which is 3.2 with a $95 \%$ confidence interval from 1.7 to 6.3 . This means that the risk of toxicity to the rat is 3.2 higher for chemicals with a $D$. magna $\mathrm{LC}_{50}<0.22 \mathrm{mg} / \mathrm{L}$ than for chemicals with a $D$. magna $\mathrm{LC}_{50} \geq 0.22 \mathrm{mg} / \mathrm{L}$.

\section{DISCUSSION}

This study was assigned to ascertain the relationship between the $\mathrm{LC}_{50}$ values of 54 chemicals for D. magna and the corresponding $\mathrm{LD}_{50}$ values for the rat to contribute to the investigation of the possibility of using invertebrate tests as prescreening methods for assessment of the toxicity of new chemicals for classification and labeling purposes.
TABLE 2

Acute Toxicity of 54 Chemical Compounds to D. magna (24-h LC $_{50}$ Values) and to the Rat (Oral LD $_{50}$ Values)

\begin{tabular}{|c|c|c|}
\hline Chemical & D. magna $\mathrm{LC}_{50}(\mathrm{mg} / \mathrm{L})$ & Rat $\mathrm{LD}_{50}(\mathrm{mg} / \mathrm{kg})$ \\
\hline Acetic acid & $10.79^{a}$ & $375^{m}$ \\
\hline Amitriptyline & $1.151^{g}$ & $380^{i}$ \\
\hline Amphetamine sulfate & $60.434^{g}$ & $55^{i}$ \\
\hline Aniline & $0.9^{b}$ & $440^{i}$ \\
\hline Arsenic trioxide & $7.5^{g}$ & $15.1^{i}$ \\
\hline Aspirin & $1,468.2^{g}$ & $1,500^{i}$ \\
\hline Cadmium chloride & $0.071^{*}$ & $88^{i}$ \\
\hline Caffeine & $683.7^{g}$ & $355^{i}$ \\
\hline Carbon tetrachloride & $69.37^{a}$ & $2,800^{m}$ \\
\hline Chloroform & $64.23^{a}$ & $800^{m}$ \\
\hline Chlorpyrifos & $0.0037^{s}$ & $145^{i}$ \\
\hline Chromous chloride & $40.501 *$ & $1,870^{i}$ \\
\hline Copper chloride & $0.172^{a}$ & $140^{m}$ \\
\hline Copper sulfate & $0.399 *$ & $960^{i}$ \\
\hline DBS & $38.514^{*}$ & $2,000^{i}$ \\
\hline DCA & $0.271 *$ & $648^{k}$ \\
\hline Diazepan & $4.271^{g}$ & $710^{i}$ \\
\hline Diazinon & $0.0009^{d}$ & $235^{q}$ \\
\hline Dichlorvos & $0.00006^{c}$ & $80^{\circ}$ \\
\hline Digitoxin & $24.21^{g}$ & $33.35^{r}$ \\
\hline Disulfoton & $0.055^{c}$ & $6.8^{i}$ \\
\hline Endosulfan & $0.620^{f}$ & $43^{\circ}$ \\
\hline Ethanol & $9,788^{*}$ & $13,700^{m}$ \\
\hline Ethylene glycol & $4,8582^{g}$ & $4,698.7^{r}$ \\
\hline Fenitrothion & $0.0002^{c}$ & $250^{i}$ \\
\hline Ferrous chloride & $74.41^{a}$ & $29.74^{m}$ \\
\hline Ferrous sulfate & $14.28^{g}$ & $319^{r}$ \\
\hline Formaldehyde & $57^{h}$ & $800^{i}$ \\
\hline Hexachlorophene & $0.1982^{g}$ & $66^{i}$ \\
\hline Isopropanol & $6,850.26^{g}$ & $5,041.6^{r}$ \\
\hline Lindan & $14.5^{g}$ & $91^{\circ}$ \\
\hline Malathion & $0.354^{g}$ & $1375^{j}$ \\
\hline Mercurous chloride & $0.0027^{*}$ & $37^{m}$ \\
\hline Methanol & $4,816^{*}$ & $13,000^{m}$ \\
\hline Methyl parathion & $0.00000031^{e}$ & $14^{j}$ \\
\hline Paraoxon & $0.00055^{*}$ & $1.8^{j}$ \\
\hline Parathion & $0.002189^{*}$ & $13^{j}$ \\
\hline$p$-chloroaniline & $13^{b}$ & $340^{n}$ \\
\hline$p$-cresol & $14^{b}$ & $1,800^{i}$ \\
\hline Pentachlorophenol & $0.44^{a}$ & $50^{m}$ \\
\hline Phenobarbital & $1,400.3^{g}$ & $162^{i}$ \\
\hline Phenol & $9.129^{g}$ & $530^{i}$ \\
\hline p-Nitrophenol & $11^{b}$ & $616^{i}$ \\
\hline Quinine sulfate & $44.8^{g}$ & $455.8^{i}$ \\
\hline SDS & $45.898^{*}$ & $1,288^{i}$ \\
\hline Sodium bromide & $15,322 *$ & $3,500^{i}$ \\
\hline Sodium chloride & $1,022.6^{a}$ & $3,000^{m}$ \\
\hline Sodium dichromate & $1.854^{*}$ & $160^{l}$ \\
\hline Sodium fluoride & $307.7^{g}$ & $180^{i}$ \\
\hline Stannous chloride & $60.8^{a}$ & $700^{m}$ \\
\hline Thallium sulfate & $8.1^{g}$ & $25^{i}$ \\
\hline Thiometon & $5.49^{c}$ & $70^{p}$ \\
\hline Toluene & $8.0^{h}$ & $7,530^{i}$ \\
\hline Zinc sulfate & $35.403^{*}$ & $2,150^{i}$ \\
\hline
\end{tabular}

${ }^{a}$ Khangarot and Ray (1988).

${ }^{b}$ Kühn et al. (1989).

${ }^{c}$ Gälli et al. (1994).

${ }^{d}$ Fernández-Casalderrey et al. (1994).

${ }^{e}$ Fernández-Casalderrey et al. (1995).

${ }^{f}$ Fernandez et al. (1993).

${ }^{g}$ Lilius et al. (1994).

${ }^{h}$ Janssen and Persoone (1993).

${ }^{i}$ Merck (1989).

${ }^{j}$ Gaines (1960).

\footnotetext{
${ }^{k}$ Merck, pers. communication

${ }^{l}$ Anger et al. (1986).

${ }^{m}$ NIOSH (1977).

${ }^{n}$ Marty and Nepierre (1979).

${ }^{o}$ Gaines (1969).

${ }^{p}$ Eto (1974).

${ }^{q}$ Gasser (1953).

${ }^{r}$ Ekwal et al. (1989).

${ }^{s}$ Kersting and

Van Wijngaarden (1992).

*This study.
} 


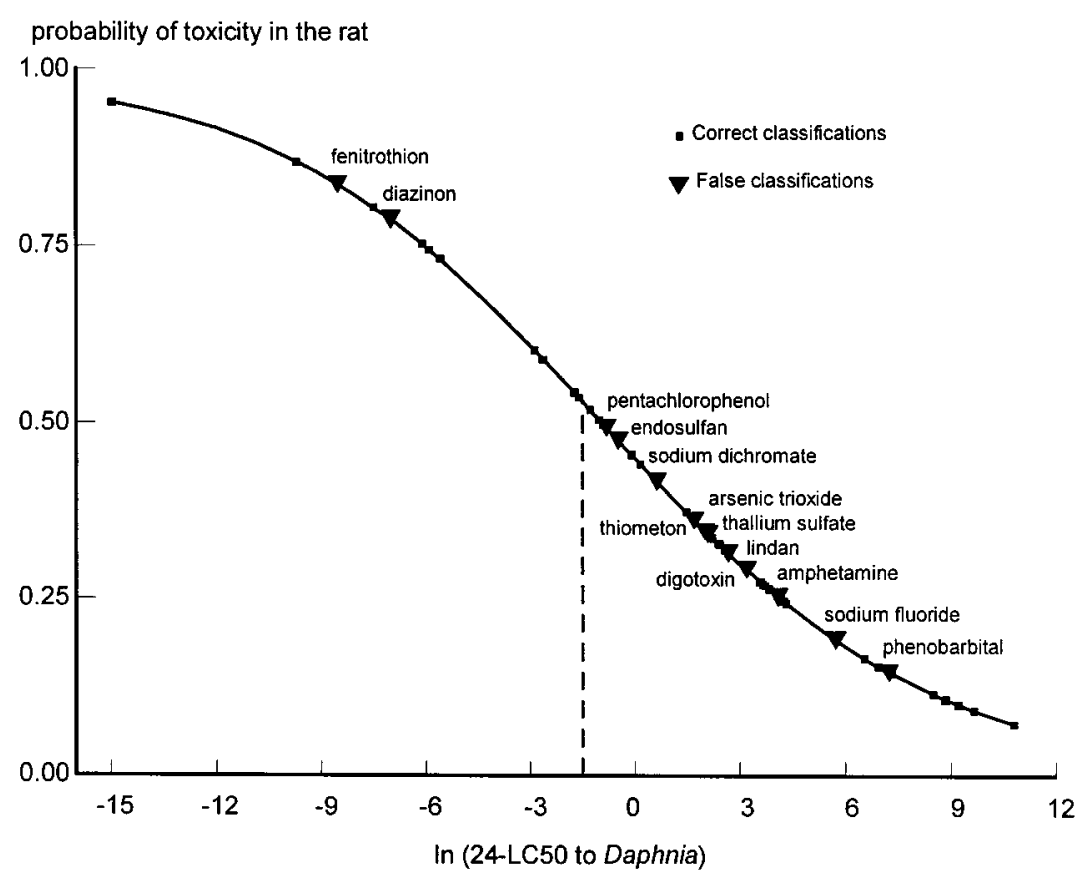

FIG. 1. Logistic curve for predicting toxicity to the rat based on D. magna $24-\mathrm{h}_{50}$, indicating the cutpoint, false positives, and false negatives.

To summarize its validity, the D. magna test is more specific than sensitive for an indication of toxicity to the rat. When it is used for a chemical that has a high probability of being very toxic to $D$. magna $\left(\mathrm{LC}_{50}<0.22 \mathrm{mg} / \mathrm{L}\right)$, the test provides considerable information if it is positive, virtually giving evidence of toxicity to the rat (with a probability of 0.83 ). On the other hand, a negative test ( $D$. magna $\mathrm{LC}_{50}>0.22 \mathrm{mg} / \mathrm{L}$ ) would not be so reliable in ruling out toxicity to the rat; the probability of correctly assigning nontoxicity to the rat is 0.74 . Therefore, the test with D. magna gives more accurate results for chemicals with a D. magna $\mathrm{LC}_{50}$ lower than 0.22 .

TABLE 3

Criterion Validity of D. magna 24-h $\mathrm{LC}_{50}$ for Prediction of Chemical toxicity to the Rat

\begin{tabular}{lccc}
\hline & \multicolumn{3}{c}{ Rat } \\
\cline { 2 - 3 } Daphnia (test) & Toxic & Nontoxic & Total \\
\hline $\mathrm{LC}_{50}<0.22 \mathrm{mg} / \mathrm{L}$ & 10 & 2 & 12 \\
$\mathrm{LC}_{50} \geq 0.22 \mathrm{mg} / \mathrm{L}$ & 11 & 31 & 42 \\
$\quad$ Total & 21 & 33 & 54 \\
Sensitivity $=10 / 21=47.6 \%$ & & & \\
Specificity $=31 / 33=93.9 \%$ & & & \\
Predictive value of a toxic Daphnia & value $\quad\left(\mathrm{LC}_{50}<0.22 \mathrm{mg} / \mathrm{L}\right)$ \\
$=10 / 12=83.3 \%$ & & \\
Predictive value of a nontoxic Daphnia & value $\quad\left(\mathrm{LC}_{50} \geq 0.22 \mathrm{mg} / \mathrm{L}\right)$ \\
$=31 / 42=73.8 \%$ &
\end{tabular}

The false-positive results were obtained for two organophosphate insecticides, fenitrothion and diazinon. The failure of this test is not surprising, as these compounds have high selectivity against insects and are known to have relatively low toxicity to mammals. Selective pesticides are examples of substances that may cause problems in the extrapolation of mammal toxicity based on invertebrate tests. However, these chemicals are derived from molecules with known active mechanisms. Thus, their toxicity could be predicted from chemical structure. False-negative classifications were obtained for 11 chemicals, including metallic compounds, organochlorine insecticides, and other organic compounds. The toxicity of these compounds to the rat, wrongly predicted by the test, demonstrates that for $\mathrm{LD}_{50}$ values greater than 0.22 the test does not perform so well, but still has a high predictive value $(73.8 \%)$. These results are in good agreement with those reported in the literature (Khangarot and Ray, 1988; Khangarot et al., 1987).

As far as validity is concerned the test performs quite well. But validity is not the only issue in question. There are ethical issues to be taken into consideration and there is no doubt that rats (and other mammals commonly used in toxicity testing) are very sensitive to pain and distress. Routine use of the D. magna test as a prescreening method will greatly reduce the number of mammals required for regulatory acute oral toxicity testing. In addition to ethical considerations, the cost effectiveness of this procedure is evident since it has a high predictive value to rat. $\mathrm{LD}_{50}$ values and daphnids are less expensive and require less 
space and human care than rats. Furthermore, D. magna is a standard organism in ecotoxicology and the acute toxicity test with this species is standardized by international organizations such as EU (1992) and EPA (1991). Using the logistic regression model, the D. magna test seems to have a predictive capacity comparable to that of mammalian cytotoxicity tests. In addition, it is an in vivo test taking into account the biotransformation of toxicants and potential integrated effects that occur in the organism as a whole, and a considerable number of $\mathrm{LC}_{50}$ values for a great variety of chemical agents already exist. Thus, use of D. magna results could be advantageous at least in some situations.

\section{CONCLUSION}

The results of this study and data published in the literature provide good evidence of the applicability of the Daphnia magna acute test as a prescreening method in toxicity testing. Exploration of the toxicity data available in the literature for this invertebrate and mammals is necessary to overcome the barriers regarding the acceptance of this alternative.

\section{ACKNOWLEDGMENT}

This work was supported by the Fundação para a Ciência e Tecnologia, program PRAXIS XXI.

\section{REFERENCES}

Abramson, J. H. (1984). Survey Methods in Community Medicine. Churchill Livingstone, London.

Anger, G., Halstenberg, J., Hochgeschwender, K., Uecker, G., Korallus, U., Knopf, H., Schmidt, P., and Ohlinger, M. (1986). Chromium compounds. In Ullmann's Encyclopedia of Industrial Chemistry (F. T. Campbell, R. Pfefferkorn, and J. F. Rousaville, Eds.), Vol. 47, pp. 67-97. Weinheim/ New York

ASTM (American Society for Testing and Materials) (1980). Standard Practice for Conducting Acute Toxicity Tests with Fishes, Macroinvertebrates and Amphibians, Rep. E-780-80.

Baird, J. D., Barber, I., Bradley, M. C., Calow, P., and Soares, A. M. V. M. (1989a). The Daphnia bioassay: A critique. Hydrobiology 188/189, 403-406.

Baird, D. J., Soares, A. M. V. M., Girling, A., Barber, I., Bradley, M. C., and Calow, P. (1989b). The long-term maintenance of Daphnia magna Straus for use in ecotoxicity tests: Problems and prospects. In Proceedings of the First European Conference on Ecotoxicology, Lyngby, 17-19 October. (H. Løkke, H. Tyle, and F. Bro-Rasmussen, Eds.), pp. 144-148.

Calleja, M. C., and Persoone, G. (1992). Cyst-based toxicity tests. IV. The potential of ecotoxicological tests for the prediction of acute toxicity in man as evaluated on the first ten chemicals of the MEIC program. ATLA 20, 396-405.

Carvalho, F., Guilhermino, L., Ribeiro, R., Gonçalves, F., and Soares, A. M. V. M. (1995). METIER (Modular Ecotoxicity Tests Incorporating Ecological Relevance). II. Ecotoxicity of poorly water-soluble compounds: concentration versus dose. Arch. Environ. Contam. Toxicol. 29, 431-434.
EEC (1992). Directive 92/32/EEC (1992/04/30). Seventh amendment of Directive 67/548/EEC Annex V. Part C: Methods for the determination of ecotoxicity. C2: Acute toxicity for Daphnia. J. O. No. L154, 5/6/1992, pp. 1-29.

Ekwall, B., Barile, F. A., Castano, A., Clemedson, C., Clothier, R. H., Diericks, P., Ekwall, B., Ferro, M., Fiskesjó, G., Garza-Ocanas, L., Gómez-Lechón, M. J., Gulden, M., Hall, T., Isomaa, B., Kahru, A., Kerszman, G., Kristen, U., Kunimoto, M., Karenlampi, S., Lewan, L., Loukianov, A., Ohno, T., Persoone, G., Romert, L., Sawyer, T., Shrivastava, R.; Segner, H., Stammati, A., Tanaka, N., Valentino, M., Walum, E., and Zucco, F. (1998). MEIC evaluation of acute systemic toxicity. Part VI. The prediction of human toxicity by rodent $\mathrm{LD}_{50}$ values and results from 61 in vitro methods. Altern. Lab. Anim. 26, 617-658.

Ekwall, B., Bondesson, I., Castell, J. V., Gömez, Lechön, M. J., Hellberg, S., Högberg, J., Jover, P., Ponsoda, X., Romert, L., Stenberg, K., and Walur, E. (1989). Cytotoxicity evaluation of the first ten MEIC chemicals. Acute lethal toxicity in man predicted by cytotoxicity in five cellular assays and by oral $\mathrm{LD}_{50}$ tests in rodents. $A T L A 17,83-100$.

EPA (Environmental Protection Agency) (1991). Methods for Measuring the Acute Toxicity of Effluents and Receiving Waters to Freshwater and Marine Organisms, 4th ed., EPA/600/4-90/027.

Eto, M. (1974). Organophosphorous Pesticides: Organic and Biological Chemistry. CRC Press, Boca Raton, FL.

Fernández, A., Ferrando, M. D., and Andreu, E. (1993). Effects of endosulfan on survival, growth and reproduction of Daphnia magna. Comp. Biochem. Physiol. C 106, 437-441.

Fernández-Casalderrey, A., Ferrando, M. D., and Andreu-Moliner, E. (1994). Effect of sublethal concentrations of pesticides on the feeding behaviour of Daphnia magna. Ecotoxicol. Environ. Saf. 27, 82-89.

Fernández-Casalderrey, A., Ferrando, M. D., and Andreu-Moliner, E. (1995). Chronic toxicity of methylparathion to Daphnia magna: Effects on survival, reproduction, and growth. Bull. Environ. Contam. Toxicol. 54, 43-49.

Finney, D. J. (1971). Probit Analysis, 3rd ed. Cambridge Univ. Press, Cambridge.

Gaines, T. B. (1960). The acute toxicity of pesticides to rats. Toxicol. Appl. Pharmacol. 2, 88-99.

Gaines, T. B. (1969). Acute toxicity of pesticides. Toxicol. Appl. Pharmacol. 14, 515-534

Gälli, R., Rich, H. W., and Scholtz, R. (1994). Toxicity of organophosphate insecticides and their metabolites to the water flea Daphnia magna, the Microtox test and an acetylcholinesterase inhibition test. Aquat. Toxicol. 30, 259-269.

Gasser. R. (1953). Regarding a new insecticide with a broad spectrum of action. Biochem. Biophys. Biol. 8, 225-232.

Guilhermino, L., Ribeiro, R., Gonçalves, F., and Soares, A. M. V. M. (1996). METIER (Modular Ecotoxicity Tests Incorporating Ecological Relevance for difficult substances). III. Effects of medium renewal and use of a carrier on the bioavailability of parathion. Environ. Pollut. 92, 97-99.

Hosmer, D. W., and Lemeshow, S. (1989). Applied Logistic Regression. Wiley, New York.

Janssen, C. R., and Persoone, G. (1993). Rapid toxicity screening tests for aquatic biota. 1. Methodology and experiments with Daphnia magna. Environ. Toxicol. Chem. 12, 711-717.

Kersting, K., and Van Wijngaarden, R. (1992). Effects of chlorpyrifos on a microecosystem. Environ. Toxicol. Chem. 11, 365-372.

Khangarot, B. S., and Ray, P. K. (1988). The confirmation of a mammalian poison classification using a water flea (Daphnia magna) screening method. Arch. Hydrobiol. 113, 447-455.

Khangarot, B. S., Ray, P. K., and Chandra, H. (1987). Daphnia magna as a model to assess heavy metal toxicity: Comparative assessment with mouse system. Acta Hydrochem. Hydrobiol. 15, 427-432. 
Kühn, R., Pattard, M., Pernak, K.-D., and Winter, A (1989). Results of the harmful effects of selected water pollutants (anilines, phenols, aliphatic compounds) to Daphnia magna. Water Res. 23, 495-499.

Lilius, H., Isomaa, B., and Holmstrom, T. (1994). A comparison of the toxicity of 50 reference chemicals to freshly isolated rainbow trout hepatocytes and Daphnia magna. Aquat. Toxicol. 30, 47-60.

Marty, J.-P., and Wepierre, J. (1979). Évaluation de la toxicité d'agents d'activité cosmétique. Cas du trichlorocarbanilide, Labo Pharma-Probl. Techn. 27, 306-310.

Merck (1989). The Merck Index, 11th ed. Merck \& Co., Rahway, NJ.

Neuhauser, E., Durkin, P., Malecki, M., and Antara, M. (1985a). Comparative toxicity of ten organic chemicals to four earthworm species. Comp. Biochem. Physiol. C 83, 197-200.
Neuhauser, E., Loehr, C., Malecki, M., Milligan, D., and Durkin, P. (1985b). Comparative toxicity of selected organic chemicals to the earthworm Eisenia fetida. J. Environ. Qual. 14, 383-388.

NIOSH (National Institute for Occupational Safety and Health) (1977). Registry of Toxic Effects of Chemical Substances, DHEW (NIOSHI) Pub. 78, 104B.

Russell, W. M. S., and Burch, R. L. (1959). The Principles of Humane Experimental Technique. Methuen, London.

Tichias, K., Fentem, J., Basketter, D., Botham, P., Brooker, P., Bruner, L., Evans, P., Fairhurst, S., Fassold, E., Fielder, R., Gerberick, F., Harvey, P., Koëter, H., Parsons, P., Schlede, E., Shannon, D., and Spielmann, H. (1998). Progress in toxicological testing: Reduction and refinement issues. ATLA 26, 619-627. 